\title{
The issue of mental health in occupational health surveillance
}

Luís Henrique da Costa Leão ${ }^{1}$

Carlos Minayo Gomez ${ }^{2}$

${ }^{1}$ Grupo de Estudos Ambientais e Saúde do

Trabalhador, Instituto de Saúde Coletiva,

Universidade Federal de

Mato Grosso. Av. Fernando Corrêa 2367, Boa Esperança. 78060-900 Cuiabá MT Brasil.

luis_leao@hotmail.com ${ }^{2}$ Centro de Estudos da Saúde do Trabalhador e Ecologia Humana, Escola Nacional de Saúde Pública Sergio Arouca, Fiocruz.
Abstract This paper addresses the issue of mental health in the Occupational Health Surveillance (VISAT) context. It seeks to present theoretical aspects and institutional policies contributing to the incorporation of mental health dimensions into the VISAT process, in view of the pressing need to attend to this demand that is becoming increasingly important in the occupational health area, especially within the scope of the National Comprehensive Occupational Healthcare Network (RENAST). Some theoretical approaches and practical experiences in mental health and work are systematically presented and discussed in this essay. A survey is also conducted of potential strategies to integrate mental health into VISAT actions. It is our view that the origins of illnesses and ensuing harm are closely linked to the elements involved in work organization and management. Consequently, surveillance practices should include and identify generating components of these negative aspects. The diversity of illnesses caused by work processes and conditions calls for major investment to ascertain and change the situations that give rise to such illnesses.

Key words Mental health and work, Health surveillance, Occupational health 


\section{Introduction}

The issue of mental health at work is currently one of the most pressing demands facing the occupational health services. The technical and social features of the way work is currently managed and organized are responsible for a series of physical, psychiatric and social illnesses ${ }^{1-4}$.

Complaints relating to bullying and psychological assaults are on the increase, along with evidence of unhappiness, exhaustion, and continuous illness. There is also evidence of more serious conditions, leading to depression, post-traumatic stress, work neuroses and even cases of suicide.

Matters such as these are already considered to be a public problem in the European Union, because they affect $28 \%$ of the workforce and are responsible for $25 \%$ of absenteeism, representing a loss of around 20 million euros to Member States.

The matter is also cause for concern in Brazil. During the first decade of the $21^{\text {st }}$ century, $33 \%$ of the economically active population suffered some form of bullying ${ }^{6}$, and in 2010 mental and behavioral problems were the third most important reason for the grant of sick leave on the grounds of incapacity ${ }^{7}$. This situation brings with it the urgent challenge of including mental health questions within the scope of Occupational Health Surveillance - Visat. For this purpose, there is a need to widen the context of interventions by adopting strategies for identifying and taking action with regard to illnesses originating in work processes at different levels, so as to include mental health in health surveillance programs.

The matter is urgent because, in addition to the increase in problems, the Reference Centers for Occupational Health (CEREST) are encountering difficulties in implementing programs in this respect ${ }^{8}$. Some teams receive requests to investigate professional categories and sectors where the problems have manifested themselves with the greatest intensity, for example in the fields of education and health. Much of the response has concentrated on an attempt to establish causes for the increase in the number of notifications under the Notifiable Illnesses System (Sinan) and to provide help for the worker suffering from illness. In some cases, in the absence of guidelines, only psychological assessments are made, using tests, clinical anamnesis and certain treatments? The most common procedure is the acceptance and registration of cases, which are then referred to Psycho-Social Care Centers (Caps) or to psy- chiatric or psychological specialists ${ }^{10}$. These are procedures concerned with treating the illness, without an analysis of the causative factors or an intervention with regard to them.

Apart from the low number of diagnoses, causes identified and cases notified, some Cerests deal with mental health as a collective problem ${ }^{11}$. They organize various events for the purpose of training their own team and local health units and for establishing partnerships with Caps and mobile mental health and psychiatric clinics so as to diagnose cases of illness, treat workers and build up the notification network. And some steps towards health surveillance and rehabilitation are taken.

Even though we do not have a complete picture of programs for mental health and work under SUS, there is evidence as to how much this topic figures in the agendas of the Cerests and in the concerns of the Ministry of Health (MH). At the same time, we note the absence of programs for systematic and continuous action, governed by guidelines and principles which will assist health surveillance strategies.

The occupational health section of the $\mathrm{MH}$ has been leading a discussion process for the purpose of formulating guidelines for care, prevention, promotion and monitoring, with the programming of meetings, seminars and workshops.

Generally speaking, under SUS, occupational mental health practice is more directed towards care and towards the recognition, diagnosis, notification and treatment of work-related mental problems ${ }^{12,13}$. In this context, there has also been a formulation of a "schedule of work-related mental illnesses" which envisaged the possibility of diagnosing and establishing a causal nexus between the mental illness and the work concerned and directing care towards those suffering from illness ${ }^{14}$.

In the light of these developments, this article aims to contribute towards the full inclusion of mental health in Visat, and to introduce some theoretical considerations for developing policies in this respect within the National Comprehensive Occupational Healthcare Network - Renast.

The reflections and suggestions set out here are the result of a systematization of theoretical and practical approaches in mental health and work in the academic and institutional fields, in the principles of the National Policy for Occupational Health, and in the experience of the authors in taking part in forums, meetings and debates on the subject. 


\section{Theory and practice in occupational mental health}

The first point to consider when we contemplate the integration of mental health within $\mathrm{Vi}$ sat concerns an understanding of the mental aspects of occupational health. Under the influence of Cartesian thought, the idea arose of the mind as a kind of interior life, separated from external events. This led to the classic division between mind and body, in accordance with which certain illnesses were located in the body, while feelings, images, hallucinations were phenomena particularly related to the mind.

Other strands of thought, originating in Freudian psychoanalysis, introduced the idea of a psychic apparatus and the notion that the processes responsible for behavior, anxiety and illness were unconscious and functioned relatively independently from corporal and cerebral processes $^{15-17}$.

More recently, through the advances in technology and the neuro-sciences, the idea has gained ground of the mind as a data processing machine, understood as a set of chemical processes and neuronal connections. And there has been a growth in psycho-pharmacological companies which control subjectivity through the use of tranquillizers and anti-depressants, leading to exorbitant profits for the pharmaceutical industry, as an expression of bio-politics and of bio-economics ${ }^{18}$.

These conceptions have influenced the modes of comprehension and action in the field of occupational mental health, and have tended to restrict the mind or psyche to simply a place where disturbances occur ${ }^{19}$, the sphere of impact of working conditions within the individual. Consequently, the cause of the illness is ascribed to the characteristics, history and personality of the worker concerned. The remedy for such problems is essentially therapeutic and psychiatric ${ }^{20}$, and little consideration is given to the processes, environment and organization of work which may have caused the illness. Psychiatric reform itself criticizes psychiatric institutions as being asylum-like and mentally disturbing, viewing the illnesses of patients as a mode of existence and not simply as a mental disturbance of the individuals concerned ${ }^{21}$.

\section{Approaches to occupational mental health}

Various views of differing persuasions have analyzed the causes of work-related illness, influenced, among other things, by the development of psychology, psychiatry and psycho-analysis, and also by the conditions in each region. We see more behaviorist views in the USA, a medical-physiological approach in Nordic countries, a sociological analysis in Latin countries and a unified approach in France.

During the course of these analyses, human suffering has been at one time or another interpreted as illness, pathology, disturbance, neurosis or depression ${ }^{22}$, so that another problem should be raised here: the medicalization and the resulting individualization, assignment of blame and victimization of problems where the cause is not in the body (biological) or in psychic factors, but in social and work relationships.

Soares and Caponi ${ }^{23}$, in their research on depression, identified the transformation of different forms of suffering into individual pathologies, measurable and homogenized through the use of diagnostic criteria. The authors also envisaged the application of "potentially universal therapeutic resources", aimed at the individual, with a special role for anti-depressants, introduced as a privileged therapeutic option.

On the contemporary scene, therefore, many illnesses which would formerly have been considered as different manifestations of life experiences now take on the features of pathologies - depression, stress, etc. One consequence for workers, given the competitive nature of the world in which they live, is a tendency to develop and maintain high levels of performance, suppressing or hiding any symptoms of illness.

Many of the illnesses of workers, being diagnosed as stress, which is a pathological mental and behavioral disturbance, tend to produce sick individuals/workers, resulting in the targeting of care and health surveillance, whilst overlooking interventions with regard to the social determinants for the illness. Pathologization and medicalization stand out at a time marked by an intolerance of illness and a demand for permanent good health. The individuals concerned end up by being socially conditioned towards the medicalization of their illness ${ }^{24}$. 
Currently there are the following approaches to the relationship between work and mental health: clinics at work, focus on stress, bullying and psychological aggression; the psycho-pathology of work and of psychiatry, including the trend towards mental exhaustion; psycho-sociology and institutional analyses; and organizational and subjective approaches.

Despite the diversity of the existing theoretical interpretations and approaches, some practice concentrates on the alternatives for lowering stress and seeks to equip workers with tools which can help them to deal with situations of stress at work. In other words, we are talking about a collective offer of guiding principles for finding individual solutions to the problems of mental health. They are prescriptive interventions, directed towards the person, and they use techniques of muscular relaxation, meditation and training in cognitive and behavioral abilities. Above all, they seek to change the evaluation of the stress-producing factors or teach people to deal with the symptoms.

In this connection, mention should be made of "coping" (strategies for adapting to adverse circumstances), and techniques of stress management, such as counselling, gymnastics, recreational and artistic activities, generally following a cognitive/ behavioral pattern. Various organizational programs also aim to reduce the cognitive evaluation of stress factors and their subsequent effects.

Few of these interventions are designed to produce changes in the principal stress factors of the organization of work. There is a tendency to explain and attribute organizational successes and failures to the individual characteristics of the persons involved, and a habit of blaming personality and life style factors of employees for their absences from work or health complaints. Moreover, psychology and medical care at work have both traditionally focused on the individual ${ }^{25}$.

These aspects are to be found in the guidelines issued by bodies such as the World Health Organization, the International Labor Organization, the Occupational Safety \& Health Administration, the National Institute for Occupational Safety and Health, the European Parliament and other national institutions.

In general, these guidelines also recommend measures to improve working environments as regards stress, violence, bullying, psycho-social risks and mental disturbance, as well as the construction of psychologically healthy companies. The crucial point to make is that most of the recommendations relate to work organization, such as the organizational culture, the control and autonomy enjoyed by the worker in his job and hours of work, interpersonal relationships, communication, social support, remuneration, recognition and home-work conflicts.

Stress, as the principal focus of concern, is viewed as a set of emotional, physiological, behavioral and cognitive reactions connected with the content, organization and context of the work $^{26}$. On this basis, rules have been established and political agreements reached, such as the European Pact on Mental Health and Wellbeing, the Edinburgh Declaration on the Promotion of Workplace Mental Health and Wellbeing ${ }^{27}$, and the Framework Agreement on Work-Related Stress $^{28}$. These are important resources for enabling the European Union to achieve the objectives of the Lisbon Strategy, which was aimed at confronting low productivity and economic stagnation ${ }^{29}$.

Bruchell and Robin ${ }^{30}$, after three decades of research, seminars, consultations and interventions, introduced into the discussion some important elements as regards constructing a healthy working environment. They emphasized trust as an essential element, based on credibility, respect and justice, and these are strengthened where there is open communication, competence and integrity in maintaining the vision of the company. Other measures are support for professional development, demonstrations of appreciation, working together with the employee in decision making and attention to aspects of his personal life, as well as impartiality, equitable dealing and the absence of discrimination.

Even though the main aim may be to increase productivity, it is impossible to ignore improvements in those aspects of work which are conducive towards the mental wellbeing of the workforce.

\section{Strategies for implementing mental health surveillance}

What are the methods for including mental health at all stages of planning, preparation, realization and evaluation of health surveillance procedures, as regards the origin of the different levels of illness to be investigated? Given that these illnesses occur at the interface of material, technical, social and organizational relations with the employees, it will be necessary to analyze the actual conditions of each working context and situation. The question of mental health may be 
the central focus of an intervention or just one of the aspects to be considered during the health surveillance process.

As regards the collection, production and analysis of information for the purposes of implementing health surveillance programs based on different data sources, reliance should be placed initially on the procedures and information which already exist under SUS for the recording of work-related illnesses, mental problems and general behavior. Included among these illnesses are cerebral lesions, personality changes, dementia, delirium, minor cognitive difficulties, organic mental difficulties, depressive episodes, fatigue syndrome, chronic alcoholism, post-traumatic stress and adaptation syndrome, professional neuroses, sleep disturbances and professional exhaustion syndrome $e^{12,13}$.

Important information can also be obtained from cataloguing and interpreting individual demands and from referrals of workers suffering from illnesses to a Cerest or from complaints made by labor organizations. Although psychic conflict, anxiety, irritability, apathy, low self-esteem and other types of psychic and psycho-social illnesses are less widely recognized, they can result in the emergence of physical symptoms $s^{31}$. And these illnesses can be a sign of collective exposure to work processes which are responsible for various manifestations of discontent or dissatisfaction, which are crucial for health surveillance.

A fundamental strategy to improve the recording of attendances, and therefore the collection of information on mental health problems - just as with other types of injury or illness is to be found in the permanents links between the Cerests and basic care services, family health teams and other units and programs in the local and regional health network, more particularly the Caps. It will also be necessary to establish inter-sectorial connections in a similar manner to the consolidated experience already gained in some sectors of production ${ }^{32}$.

\section{Integrated analysis of the work process}

Mental health phenomena - various illnesses, melancholy, sadness, depression, bullying, stress, disturbances, etc - are specific conditions, but they can be interlinked with problems arising from exposure to various kinds of risk in the work environment, as well as the occurrence of work-related accidents. It is this complex interface between workers and the material, physical, chemical, biological, cultural and organizational aspects of work procedures which should be the object of health surveillance.

When in the practice of interventions there is a rigid distinction made between the objective and subjective aspects of work, this is a simplification of reality. And mental health ends up by being considered a problem of the workers, a subjective, interior, individual question, and this works in favor of blaming and victimizing the symptoms of illness on the part of workers. Moreover, this compartmentalization of mental health as part of the "internal world" can contribute towards maintaining the invisibility of those aspects of the work process which cause pressure and lead to the outbreak of illness. And at the same time it contributes towards the continuation of psychologizing and medicalizing attitudes, to the extent that it refers to the clinic, on the one hand, the problem of understanding and treating subjective aspects (difficulties, illness and disturbances) and, on the other hand, it resorts to health surveillance to identify objective aspects.

A holistic analysis of the work process avoids creating a dichotomy in analysis/intervention between the physical, material, objective aspects and the subjective, mental-interior, psychological aspects. Thus Visat needs to surmount the segregation between "the outside and the inside" of subjects.

This holistic analysis of the work process includes a general assessment of the processes of production (political, economic, technological and social), the specific characteristics of work processes (raw materials, artefacts, procedures, etc), the burdens and risks of the workplace (physical, chemical, biological, ergonomic), the aspects connected with the organization of labor (the division of tasks, hierarchy, management methods, working hours, shifts, rhythm and intensity of tasks, breaks), the level of the activity and real work (relationships, creations, illnesses, defenses, production of new rules).

In our view, this integrated approach provides support for collective negotiations and the initiation of changes in work processes for the benefit of mental health. On the other hand, to isolate mental health from the other problems which exist in the work processes which are the subject of intervention could leave the Visat professionals deprived of support for referring actions to the competent bodies and could make it difficult to implement effective changes to the work. Obviously mental health has its specific aspects, but it cannot be treated in an isolated manner, because 
every material, symbolic and social aspect of the work is interlinked with the subjects.

The wholeness of work, as a social, economic-material and psychological-symbolic question, should not be split up to assist the success of interventions in one or other aspect of reality. A dismissal, excessive charges, accidents, new rhythms, relationships, working hours, salaries, among other matters, affect the pictures the subjects have of themselves, of others and of the work. Work arouses various feelings - satisfaction, frustration, fear, indecision, doubts, sadness - among workers and all collective manifestations of illness ought to point health surveillance towards the work, in order to understand its contradictions and propose effective changes to improve wellbeing.

These assumptions as to the transversal nature of work - mutual interplay between subjects and working environment - contribute towards the adoption of more holistic practices, avoiding compartmentalization in the analysis of work processes.

\section{Aspects of the organization of work}

In our view, the intervention process, whether or not the main focus is on mental health, means a thorough scrutiny of the work process, that is to say, an assessment of the whole work system, by looking at all its components: environment and work process, premises, equipment, characteristics of the workers, operations, activities, flows, inventories, management mechanisms, organizational culture. All these elements are crucial and actions which seek to minimize illnesses need to give more importance to the organization and management of work, because this is the element which defines the rules and functions for making the whole system work.

By work organization (WO) we do not mean a place, an institution or an environment, but the ways of devising the work process, the technical and social arrangements which standardize behavior, establish targets, objectives, aims, culture and values, and organize and train personnel.

Among the various elements of WO are hierarchies and the rules of superiority, the routines and prescribed activities, the division of tasks, the rhythms of production, the mechanisms for the control of production, the sequence of production flows, the working hours, shifts and breaks, alternation, substitution and replacement, oral and written rules and instructions, formal and informal communication, systems for bonuses and sanctions, requirements of operators and safety and protection mechanisms, and medical control.

WO, whether in manufacturing industry, services or agriculture, is shaped by technical and social considerations, and in theory unites material elements (raw materials and objects of work), technical and technological features (machinery, equipment, instruments), and social and cultural aspects (divisions, groups, status, recognition, power relationships, interpersonal relationships, values, beliefs, habits) with the characteristics of the subjects.

Each work context, therefore, shows a specific conjunction of these elements, and therefore has its own characteristics in the form of positive or negative interference in the health-sickness process and in the appearance of illness. It is therefore necessary to stress these elements of work organization to legitimize intervention with regard to their constituent aspects, such as the relationship between management and workers, abusive rules, excessive demands, productivity criteria, and injustices in relationships, among other matters. This means progress as regards the de-naturalization of the organization of work.

In order to change aspects of the organization of work it is necessary to carry out a critical analysis, including the observation of work relationships and daily working details. For this purpose, open interviews can be held with workers and management, and larger meetings between workers representatives and specialists in that type of work. The overall intention is to generate dialogue which will lead to an understanding of the day to day aspects, the sources of problems and the possible solutions.

One fundamental question is a proper assessment of the type of sector and the management process. If there is management which concerns itself with programs for quality of life at work, for example, if it already has this kind of sensibility, health surveillance will deal with other management which is more open to making changes. Here there is a platform for dialogue, because there are convergences and a possible readiness to review processes, procedures and relationships. In the same way, if a company is resolved to change its image for reasons of marketing or because of falls in productivity and high staff turnover rates, such concerns can run contrary to what health surveillance is looking to do. In such cases, health surveillance can fulfill a more educational role.

At the same time, an assessment must also be made as to whether the problem also lies in a 
"culture of disorganization", where there are no collective mechanisms for decision making and the rules are defined by a rigid and personalized hierarchy, or whether one is dealing with a culture which is more democratic and open to dialogue.

We set out below certain elements of the organization of the work process which health surveillance should look at, as initial markers for affording a closer view of the sources of problems. They can be grouped under eight headings: (1) organization of time and intensity of production; (2) management practices; (3) organizational culture; (4) interpersonal relationships; (5) activity and autonomy; (6) relationship of subjects with their activities; (7) situations relating to the employment relationship; (8) matters outside the work process.

The first aspect deals with the rhythm of work and the workload, including the length and intensity of the working day, whether there is a system of shifts or other situations which could cause tiredness or exhaustion, changing the behavior of the workers and potentially provoking serious crises. Excessive workloads, the speed at which tasks must be performed, the demands of night work, for example, when analyzed in an integrated way, supply indications as to the extent the work can cause disturbances for the subjects.

Management practices are also an essential aspect, because they are concerned with all the ways that the actions of some affect others. They define the methods by which workers are selected, trained, paid, awarded bonuses and incentives, and evaluated. They also involve the kinds of technology employed, the demands/targets for productivity and payment by production, and the procedures for the assessment of performance and results. These procedures, irrespective of their extent and degree of qualification, and whether carried out informally or by qualified professionals and specific instruments, have repercussions for those subject to them which are crucial for health surveillance.

Another important point involves the components of the organizational culture: the most common forms of communication, such as opportunities for workers to explain their grievances and take part in the decision making process, the values, habits and beliefs to be found among the workforce in daily working life, and the organizational structure itself, including the aims, mission, history and vision for the future of the organization. One aspect of health surveillance tries to discover if there is transparency in management, respect for people, appreciation of the efforts of workers to resolve problems, incentives for improving their lives, and opportunities for promotion. After all, it can be very wearing to have to face a long and tiring working day, a long journey between home and work, and an authoritarian management, along with all the other problems. This is an ample field for relationships. The health surveillance process proceeds to identify the greatest possible number of work organization elements, so as to obtain the closest view of the situations faced by the workers every day, because it is they who will be showing the symptoms of problems. These symptoms may express themselves as situations of discontent because they are not being heard, dissatisfaction with management, discouragement through working in a poor environment, without the necessities for the full and proper performance of their tasks owing to the lack of materials, equipment or personnel.

Another area which produces problem situations is undoubtedly interpersonal relationships. It is in this area that we find abusive behavior, psychological and symbolic violence, unequal power relationships and disciplinary mechanisms. Included here are incentives for competitiveness or for collaboration and teamwork, relationships with others and respect for differences in sex, age, function, color, ethnic origin and religion. Relationships between workers can produce situations of (dis)trust, (in)justice, lack of recognition and humiliation. These relationships can be the source both of suffering and of resilience. The support of the group, the forging of friendships or a spirit of comradeship, are certainly factors which contribute towards an improvement of mental health among workers.

The autonomy and other aspects of the activity of workers are also important to assess. It is a question of the control enjoyed by the worker over his tasks, the clear definition of his role and what is expected of him, and the balance between capabilities and requirements. It is very important to pay attention to the existence or lack of autonomy and freedom of choice, decision making, problem solving and even the management of work times. This item also includes the pride of the worker in the type of work that he does and in the product, and even the feelings produced by the task he has to perform, such as feelings of inferiority or low self-esteem.

There is also a level which deals with the actual relationship of workers with their activities. It includes the emotional pressures on the worker, the feeling of capability/incapability for the task, 
the underemployment of his knowledge and abilities, and the meaning and significance of the work for him, among other aspects.

Even the type of employment relationship has its influence in generating health problems. Instability in employment, temporary contracts, informality and the threat of job loss lead to anxiety, fear and conflict, because they threaten the actual subsistence of the worker and his family. Harmony between private life and work, or the lack of it, also has repercussions as regards illness, as do the actual conditions of housing and transport and the pay received.

Many of these matters are central historical complaints of workers to ensure improvements in their living standards and work. It is very important to focus on them to identify and reduce the causes of illness. For this purpose, whatever methodology and instruments are employed, there is a fundamental requirement to listen to the arguments of workers, safety experts, management and others involved in the work. This is because many situations that give rise to health problems are invisible to third parties and can only be understood through what the workers say and how they behave and express themselves ${ }^{33}$.

These elements may be considered for the purposes of understanding the reasons for complaints, so that interviews with workers are not simply an opportunity for confessions, but a way to identify the principal problems in work relationships.

In a similar manner to other health surveillance practices, it is also important to identify and analyze documents relating to health and safety - absences from work, rates for the frequency and seriousness of accidents and occupational illnesses, medical control practices for mental health, resolutions of the CIPA (Internal Committee for the Prevention of Accidents), existing quality programs, rates of absenteeism and staff turnover - and also those relating to management practices, such as company mission statements, written codes, incentive and bonus mechanisms, management reports and productivity indices, among others.

All this information will allow the construction of a kind of map for the organization of work, with the input of workers, technical experts, managers and public health workers, so as to locate the most obvious and immediate relationships and causes of problems and to identify the critical points to be addressed.

As to the methods for evaluating, initiating and monitoring the results of action, relevant considerations are collective bargaining processes, sectorial agreements and the mechanisms for implementing changes in the organization of work. The aim is therefore to recommend, carry out and monitor changes based on the analysis of the elements previously identified. It involves more than simply obtaining evidence of links in a causal chain between a subject and an illness, the idea is to overcome positivist and biomedical emphases to deal with the manifestations of health problems.

More than generating administrative processes, the aim of health surveillance is to systematize the required changes and track their introduction and effectiveness in a dialogue with the responsible personnel. From this standpoint, the incorporation of knowledge and experience is a basic requirement at all the other stages of the health surveillance process. The mobilization of workers and their representatives for the identification and resolution of situations which give rise to mental health problems at work is a crucial step forwards. It is essential to strengthen strategies for assisting workers and to take advantage of their leading role in identifying and analyzing their work, with a view to changing aspects of the way their activities are organized. The recognition and better identification of the origins of problems in elements of WO depends more on the role of the workers than that of the technical experts.

The effective participation of workers as the real protagonists at all stages of action contributes towards changing the role of the worker as a mere means of production at the work level, an object to be cured at the health level, and a recipient of assistance at the social security level, so as to strengthen his autonomy when the subject of changes.

\section{Final considerations}

In this article, we have sought to present the theoretical aspects and institutional policies which contribute towards incorporating mental health considerations in occupational health surveillance processes. There is a need to respond to this demand, which is becoming increasingly explicit in the area of occupational health. It is our view that the causes of illnesses and threats to health bear a strict relationship with the elements which comprise the organization and management of work. Thus, health surveillance actions must include and identify the factors responsible for these threats. The diversity of health problems caused 
by work conditions and processes demands a big investment in investigating and transforming the situations which give rise to such problems.

At a national level, it is important to encourage the inclusion of worker mental health problems in legislation and the technical rules governing health surveillance. Similarly, it is necessary for the Ministry of Health to issue specific guidelines to achieve advances in health surveillance programs.

To make progress in this direction is an enormous challenge, principally because we still do not have sufficient consolidated experience of health surveillance in this field.
Finally, it should be stressed that to make the results of worker mental health surveillance effective is not merely a technical question. To intervene in the management and organization of work means entering an area where there is a conflict of mutually antagonistic interests at various levels, and there are therefore limits to such actions. It is consequently necessary to think of means and strategies to negotiate changes which will lead to greater work satisfaction. Clearly the workers themselves must play a fundamental role at all stages of health surveillance to ensure the implementation of changes.

\section{Collaborations}

LHC Leão worked on the research and the initial version of the article; C Minayo Gomez worked on the concept and the final version of the article. 


\section{References}

1. Renault E. Du fordisme au post-fordisme: Dépassement ou retour de l'aliénation? Actuel Marx 2006; 1(39):89-105.

2. Renault E. Soufrance Sociales. Philosophie, psychologie et politique. Paris: Editions la Découverte Paris XIII; 2008.

3. Gorz A. O imaterial. Conhecimento, Valor e Capital. São Paulo: Anablume; 2005.

4. Lazzarato M, Negri A. Trabalho imaterial. Formas de vida e produção de subjetividade. Rio de Janeiro: DP\&A; 2001.

5. Agência Europeia para a Segurança e a Saúde no Trabalho (OSHA). Estresse relacionado com o trabalho. Facts 2002; 22. 4p.

6. Confederação Nacional do Ramo Químico (CNRQ). Assédio Moral: A tirania nas relações do trabalho. São Paulo: Lavra; 2004.

7. Silva-Junior JS. Afastamento do trabalho por transtornos mentais e fatores associados: um estudo caso-controle entre trabalhadores segurados da previdência social [dissertação]. São Paulo: Faculdade de Saúde Pública; 2012.

8. Leão LHC, Castro ACC. Políticas públicas de saúde do trabalhador: análise da implantação de dispositivos de institucionalização em uma cidade brasileira. Cien Saude Colet 2013; 18(3):769-778.

9. Sato L, Lacaz FAC, Bernardo MH. Psychology and the Workers' Health Movement in the State of São Paulo (Brazil). J Health Psychol 2004; 9(1):121-130.

10. Leão LHC, Castro AC. Processos históricos da implantação do Centro de Referência em Saúde do Trabalhador (CEREST) no município de Campos dos Goitacazes RJ. In: Anais do VIII Encontro do Núcleo Clio-Psyché; 2008; Rio de Janeiro. p. 205-207.

11. Santos APL, Lacaz FAC. Saúde do trabalhador no SUS: contexto, estratégias, desafios. In: Gomez CM, Machado JHM, Pena PGL, organizadores. Saúde do Trabalhador na Sociedade Brasileira Contemporânea. Rio de Janeiro: Fiocruz; 2011. p. 87-106.

12. Brasil. Ministério da Saúde (MS). Doenças Relacionadas ao Trabalho: Manual de Procedimentos para os Serviços de Saúde. Brasília: MS; 2001.

13. Brasil. Portaria no 1.339 , de 18 de novembro de 1999. Institui a lista de doenças relacionadas ao trabalho, a ser adotada como referência dos agravos originados no processo de trabalho no Sistema Único de Saúde, para uso clínico e epidemiológico. Diário Oficial da União 1999; 19 nov.

14. Brasil. Ministério da Saúde (MS). Protocolo de agravos à saúde mental relacionados ao trabalho. Brasília: MS; 2005.

15. Freud S. O mal estar na civilização. Rio de Janeiro: Imago; 1974.

16. Mezan R. Freud, a trama dos conceitos. São Paulo: Perspectiva; 1982.

17. Azevedo VAZ. Algumas contribuições da psicanálise ao campo de conhecimento da saúde mental no trabalho [tese]. Campinas: Unicamp; 2003.

18. Rose N. Neurochemical selves. Society 2003; 41(1):4659.

19. Ricouer P. La souffrance n'est pas la douleur. Autrement 1994; 142:58-69.
20. Amarante P. Saúde mental e atenção psicossocial. Rio de Janeiro: Fiocruz; 2007.

21. Quintas R, Amarante P. A ação territorial do Centro de Atenção Psicossocial em sua natureza substitutiva. Saúde em Debate 2008; 32(78/80):99-107.

22. Brant LC, Minayo-Gomez C. A transformação do sofrimento em adoecimento: do nascimento da clínica à psicodinâmica do trabalho. Cien Saude Colet 2004; 9(1):213-223.

23. Soares GB, Caponi S. Depressão em pauta: um estudo sobre o discurso da mídia no processo de medicalização da vida. Interface (Botucatu) 2011; 15(37):437-446.

24. Caponi S. Viejos y nuevos riesgos: en busca de otras protecciones. Cad Saude Publica 2007; 23(1):7-15.

25. Kompier MAJ, Kristensen TS. As intervenções em estresse organizacional. Cad. Psicol. Soc. Trab. 2003; 6:3758.

26. Comisión Europea. Guía sobre el estrés relacionado con el trabajo. ¿La "sal de la vida" o el "beso de la muerte"? Luxemburgo: Oficina de Publicaciones Oficiales de las Comunidades Europeas; 2000.

27. European Network for Workplace Health Promotion (ENWHP). The Edinburgh Declaration on the Promotion of Workplace Mental Health and Wellbeing. 2010 out. [acessado em 2013 ago 18]: [2 p.]. Disponível em http:// www.enwhp.org/fileadmin/downloads/publications/ Edin- burgh_Declaration.pdf

28. Social Dialogue. Framework agreement on work-related stress. 2004 out. [acessado em 2013 ago 19]: [4 p.] Disponível em: http://ec.europa.eu/social/BlobServlet?doc Id $=1479$ \&lang-Id $=$ en

29. Malgorzata M, Xabier I, organizadores. Drivers and barriers for psychosocial risk management: an analysis of the findings of the European Survey of Enterprises on New and Emerging Risks (ESENER). Report. Luxembourg: Publications Office of the European Union; 2012.

30. Bruchell M, Robin J. The great workplace: how to build it, how to keep it and why it matters. São Francisco: Willey; 2011.

31. Bernardo MH, Garbin AC. A atenção à saúde mental relacionada ao trabalho no SUS: desafios e possibilidades. Rev. bras. saúde ocup. 2011; 36(123):103-117.

32. Minayo-Gomez C. Produção de conhecimento e intersetorialidade em prol das condições de vida e de saúde dos trabalhadores do setor sucroalcooleiro. Cien Saude Colet 2011: 16(8):3361-3368.

33. Vasconcellos LCF, Gaze R. Técnicas de análise de riscos, cargas de trabalho e situações de vulnerabilidade. In: Ministério do Planejamento, Orçamento e Gestão (MPOG). Políticas Públicas de Saúde. Servidor Público Federal. No prelo 2014.

Article submitted 29/08/2014

Approved 29/08/14

Final version submitted 08/09/2014 